\title{
Collaborative workplaces for innovation in service companies: barriers and enablers for supporting new ways of working
}

\author{
Claudia Manca $^{1,2}$ (D) Mercedes Grijalvo $^{2} \cdot$ Miguel Palacios $^{3} \cdot$ \\ Matti Kaulio ${ }^{1}$
}

Received: 19 June 2017/ Accepted: 22 December 2017/Published online: 5 January 2018

(C) The Author(s) 2018. This article is an open access publication

\begin{abstract}
The paper aims to provide a systematic overview of the barriers and enablers that contribute to the success or failure of collaborative workplaces initiatives aimed at fostering innovation in service companies. The study is based on semi-structured interviews with innovation managers, human resource managers and facility department executives from a sample of multi-national service companies. Its primary focus is on the workplace initiatives carried out in their Spanish subsidiaries. The paper contributes to the extant research by identifying a conceptual model for collaborative workplaces and by providing a systematic overview of the related barriers and enablers. From the interviews, these factors were organized within a framework usable by practitioners for analysis. This paper is of interest to companies that aim to design collaborative workplace strategies to justify associated investments. It can also provide their managers with guidelines to lead the company in the transition toward new ways of working based on higher employee collaboration and flexibility.
\end{abstract}

Claudia Manca

claudia.manca@indek.kth.se

Mercedes Grijalvo

mercedes.grijalvo@upm.es

Miguel Palacios

mpalacios@escpeurope.eu

Matti Kaulio

matti.kaulio@indek.kth.se

1 KTH Royal Institute of Technology, Stockholm, Sweden

2 UPM Universidad Politécnica de Madrid, Madrid, Spain

3 ESCP Europe, Madrid, Spain 
Keywords Collaborative workplace $\cdot$ Alternative workplace $\cdot$ New ways of working $\cdot$ Collaboration $\cdot$ Enablers · Barriers · Tensions $\cdot$ Service companies

\section{Introduction}

Digital technologies have driven new patterns of collaboration within companies. Today, collaboration does not occur only within clearly defined organizational boundaries. It crosses distance and organizational structures, resulting in dynamic teams whose members are selected from different workgroups both inside and outside of the company (Pentland 2012; Chen and McDonald 2015). Changes in the communication patterns affect knowledge sharing and innovation processes by leading to the emergence of cross-pollination of ideas between workgroups and to the need for continuous coordination across functions (Hill and Gareth 2009; Fleming 2004; Coradi et al. 2015b).

In this scenario, established companies are facing major challenges. They are forced to rethink traditional collaboration dynamics and structures, which are rooted in hierarchical and bureaucratic organizational models (Barley and Kunda 2001). This challenge is particularly salient in the context of service businesses, where the focus on customers for new service development implies the need to integrate heterogeneous functions and business units in the value-creation process (Ostrom et al. 2010).

To face this challenge, an increasing number of service companies set up collaborative workplaces (CWs) where innovation can flourish. These spaces combine initiatives aimed at sustaining collaboration and knowledge sharing and span different organizational areas, including workplace design, digital technologies and flexible work practices (Apgar 1998; Davenport et al. 2002; ten Brummelhuis et al. 2012; Van Der Voordt 2004).

Despite the fact that companies increasingly experiment with initiatives in these areas, scholars still claim "an astounding lack of knowledge about what actually improves performance" (Davenport et al. 2002, p. 25). Consequently, the success behind the adoption of $\mathrm{CW}$ strategies is mostly an article of faith rather than the result of scientific evidence (Davenport et al. 2002; Waber et al. 2014). As a result, the effectiveness of alternative workplace strategies in sustaining collaboration and innovative dynamics has been the subject of intense academic debate.

Past research in knowledge and innovation management found that companies and managers can support innovation by designing spaces that aid collaboration among people (McCoy 2005; Oksanen and Ståhle 2013; Moultrie et al. 2007; Stryker et al. 2012; Haner and Bakke 2008). For example, companies can provide doodle spaces, collaborative platforms and balanced layouts that support the heterogeneous work modes of knowledge creation (Lee 2016; Nonaka 1994).

Nonetheless, there is also evidence that open and collaborative workplace platforms might be associated with negative attitudes (Carlopio and Gardner 1992; 
Brennan et al. 2002; Oldham and Brass 1979) that hamper collaborative and innovative behaviors (Waber et al. 2014).

The existence of the possible side effects of CWs necessitates a closer examination of the factors that may facilitate and hinder collaborative dynamics in this type of office environment. To do this, we address the following research questions.

1. What are the internal contingency factors (barriers and enablers) that hinder or facilitate the adoption of collaborative workplaces by companies?

2. How do companies and managers deal with internal contingency factors in order to undertake and sustain collaborative workplace initiatives?

Specifically, we address these questions in the context of established service companies, which heavily rely on multidisciplinary innovation groups and might face additional challenges due to the existing culture and structures.

The paper is structured as follows. First, it proposes a conceptual model that tries to facilitate the understanding of the $\mathrm{CW}$ phenomenon. The model is based on the synthesis of the literature investigating the link among the workplace, collaboration and innovation. Thereafter, the paper provides a systematic overview of the internal contingency factors that influence the ability of service companies to undertake, design and successfully deploy CW initiatives. Finally, the conceptual model is used as a cognitive tool to interpret our results. The paper concludes with a summary of the main findings, managerial implications and suggestions for further research.

\section{Drawing a conceptual model for collaborative workplaces}

Prior research investigating the link among workplace design, collaboration and innovation suggests that the transition toward CWs involves a plurality of deployment areas that are briefly described below.

Physical layout and facilities: The physical workplace may be designed to aid collaboration and knowledge sharing both between and within groups (Vischer 2007; Elsbach and Bechky 2007; Coradi et al. 2015a; Boutellier et al. 2008; Stryker et al. 2012). Recently, a team of researchers from Harvard University found that CWs designed to foster workplace mobility can positively affect innovation by increasing the number and frequency of impromptu meetings among employees (Waber et al. 2014). Besides, the research suggested that companies and managers can leverage the symbolic dimension of the physical work environment to create an attractive, value-reflecting space that is conducive to autonomy, innovation and organizational learning (Oksanen and Ståhle 2013; Vischer 2011).

Information and communication technologies: With the increased use of mobile and multi-locational work, physical workplaces are no longer the sole work locations, and workplace design should take into account digital work (Lee 2016; Waber et al. 2014; ten Brummelhuis et al. 2012; Nonaka and Konno 1998). In the context brought by new ways of working, distance-shrinking technologies are 
fundamental to sustain collaboration among physically and temporally distributed employees. They provide the company with access to a wider knowledge stock that resides inside and outside the company and can be used as a source of innovative ideas (Davenport and Prusak 2000).

Human resource and work practices: CWs do not rely only on the available technologies and the physical workplace arrangements; HR and work practices also contribute to shaping behaviors and communication patterns. CWs often involve the adoption of flexible work practices that provide people with the flexibility to collaborate across workgroups and functions, depending on the activity requirements (Bean and Eisenberg 2006; Ten Brummelhuis et al. 2011; Hoeven and Zoonen 2015; Gerdenitsch et al. 2015). This affects communication efficiency, information sharing and workplace support relationships (Collins et al. 2016; Gajendran and Harrison 2007). Workplace mobility supports quick transfer of ideas and the formation of flexible workgroups through increased impromptu interactions (Haner and Bakke 2008; Penn et al. 1997).

Organizational culture and structure: The last deployment area that needs to be aligned with previous ones to sustain $\mathrm{CW}$ initiatives is organizational culture and structure. In their study on multi-locational knowledge work, Bosch-Sijtsema and colleagues identified organizational culture and policies among the contextual factors impacting team performance, together with the physical and digital workplace infrastructure (Bosch-Sijtsema et al. 2011). Through the leveraged office design concept, Elsbach and Bechky conveyed the image of an office where physical layout, technologies and managerial practices are synergic in supporting communication and knowledge sharing between groups (Elsbach and Bechky 2007). Listing organizational culture among the CW deployment areas is also in line with prior findings by McElroy and Morrow (2010). They concluded that the physical environment is only one of the elements that need to be aligned to support organizational change. Technologies, organizational structure and work practices are also involved. The alignment among different elements is required to avoid mixed messages sent to employees about organizational values and the assumptions underlying the workplace interventions.

Therefore, we argue that $\mathrm{CW}$ identifies a combination of non-conventional layouts, facilities, technologies and work practices that aim to sustain knowledge work performance and innovation by providing an attractive, smart and value-reflecting workplace that aids collaboration, operational flexibility and cultural change.

To draw a comprehensive conceptual model to analyze CWs, we draw upon the framework originally proposed by Chan et al. (2007) to describe the various dimensions that are involved in the workplace design process. Those dimensions include organizational design, information technology and facility management, which were linked to financial performance. Each dimension in the original framework is generally represented by a group or department in the company. Their respective objectives can be in contrast with one another and, therefore, can 
generate tensions between the different areas that have been overlooked by prior studies (Chan et al. 2007).

By proposing a modified version of the model (Fig. 1), we tried to overcome the departmental view and link workplace interventions to the overarching organizational culture and structure rather than to the financial dimension. This is in line with the scope of $\mathrm{CW}$ initiatives that are meant to favor the shift of established companies from bureaucratic models to different ones that are less hierarchical and more reliant on cross-functional relationships (Barley and Kunda 2001). Thus, our model highlights the organizational areas that need to be aligned to sustain the transformation toward CWs.

As in the original framework, this model suggests the existence of interactional effects between the different deployment areas, such as tensions and complementarities. These might affect CW performance, including the ability to sustain innovative ways of working, entrenched in enhanced collaboration and knowledge

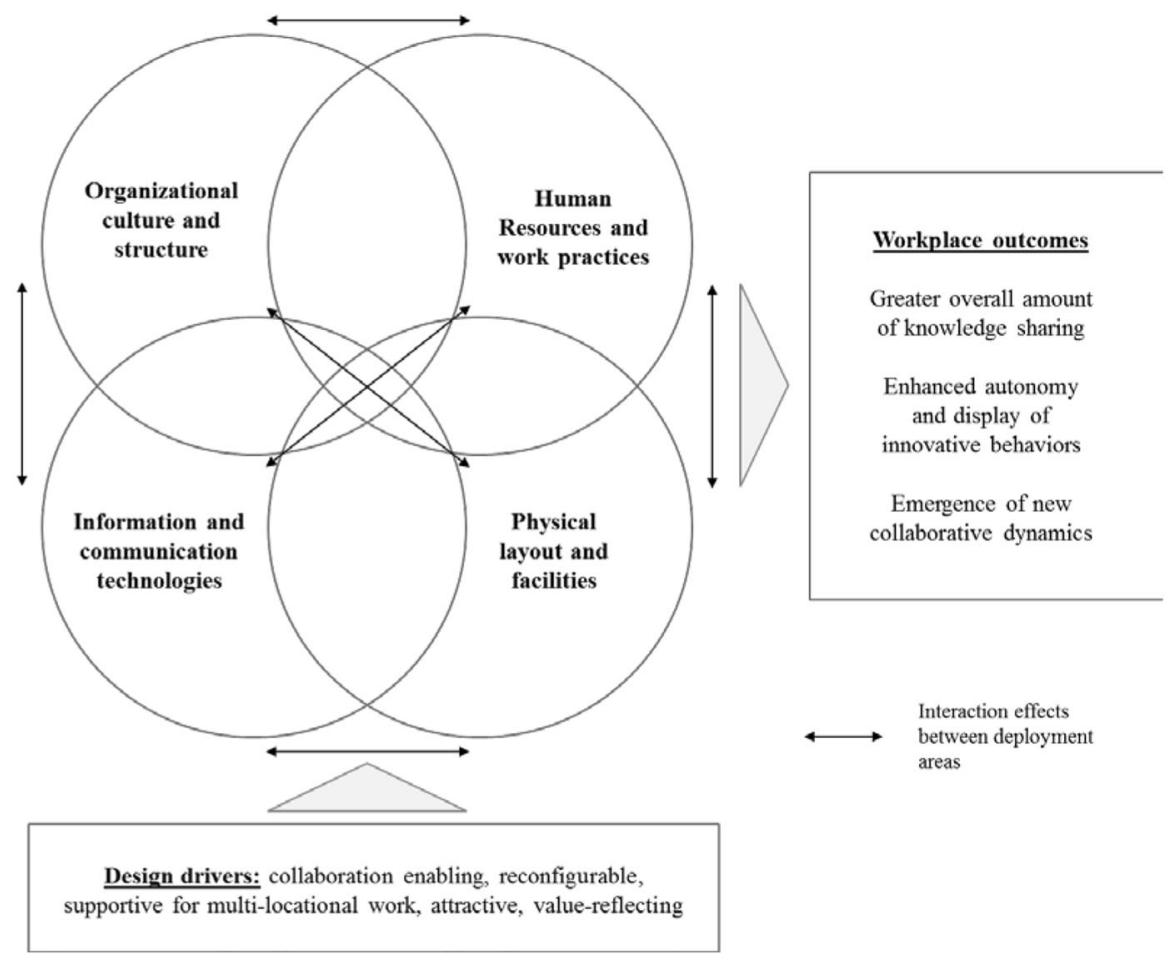

Fig. 1 Collaborative workplace: a conceptual framework. An elaboration of Chan et al. (2007) 
sharing. Therefore, we apply this framework to analyze how the contingency factors detected through the empirical fieldwork affect $\mathrm{CW}$ performance.

\section{Research methodology}

The objective of this study is to explore the internal contingency factors for CWs and how companies deal with them to sustain CW performance. To address this objective and explore the CW phenomenon in its real-life setting (Yin 1989), we designed an in-depth interview study that involved managers and executives from a panel of selected case companies. Specifically, we devoted our attention to the Spanish branches of multinational service companies. These companies were picked from heterogeneous industries, including banking and finance, education, telecommunications, consulting and engineering, to ensure the representation of different service industries. Case selection was conducted by identifying established service companies with at least 15 years of business experience and that recently introduced $\mathrm{CW}$ initiatives in a plurality of deployment areas. This will allow us to analyze different approaches to $\mathrm{CW}$ and interactional effects among deployment areas. In Table 1, we provide a brief description of the selected cases, which are also mapped according to the involved deployment areas in Fig. 2.

We used a purposive sampling (Eisenhardt 1989; Yin 1989) and collected data from managers and executives in different organizational areas that are typically involved in $\mathrm{CW}$ deployment, including human resources, facility management and innovation management. A total of eleven in-depth interviews were conducted. When possible, the interviews were tape-recorded, transcribed and subsequently coded following an inductive approach (Gioia et al. 2012). We then looked for recurring themes that cut across the cases.

The interviews were semi-structured and used a protocol that included open questions on the implemented initiatives and the related contingency factors. Interviews were kept broad in scope in order to get a broader range of themes and contingencies. Critical incidents were also collected and were at least one for each case.

Reliability was achieved using interpretative notes that were created for each case in order to integrate cross-case comparisons, field observations and external documents (Miller and Crabtree 1992). For further information on the sources of evidence, please refer to Table 1.

\section{Findings}

This section presents the empirical findings from the interview study. These results are synthesized in Table 2. Then, we discuss the recurring barriers and enablers, in which the order is dictated by the factor's frequency in the sample. 


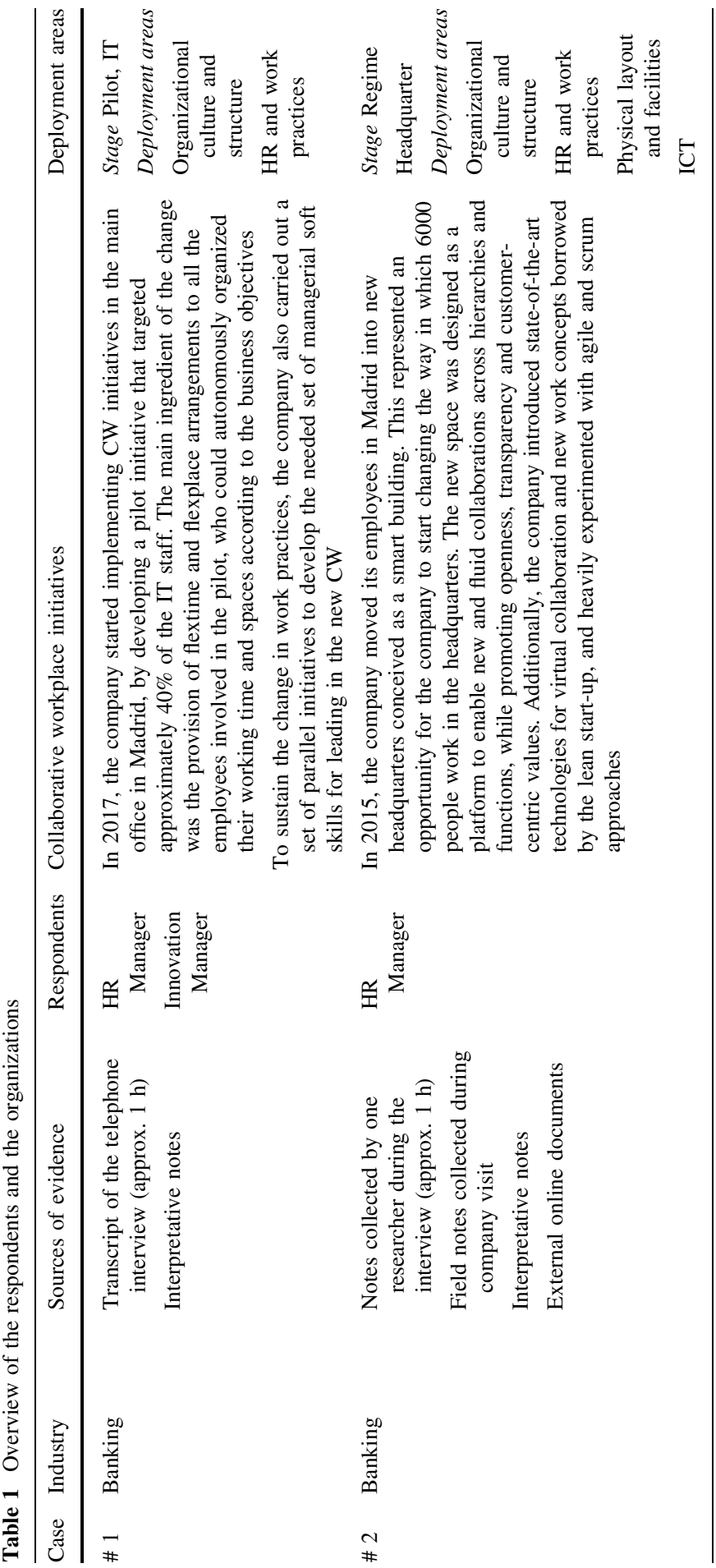




\begin{tabular}{|c|c|c|}
\hline \multirow[b]{2}{*}{ 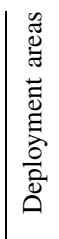 } & \multirow[b]{2}{*}{ 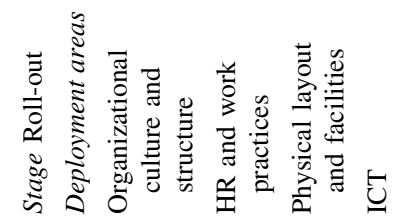 } & \multirow[b]{2}{*}{ 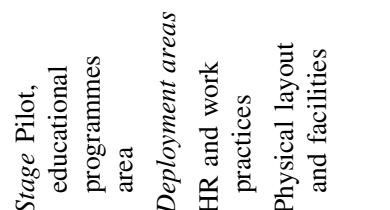 } \\
\hline & & \\
\hline & 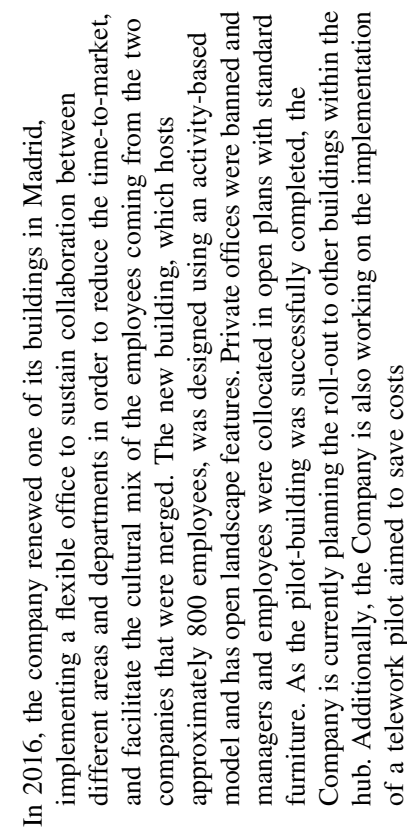 & 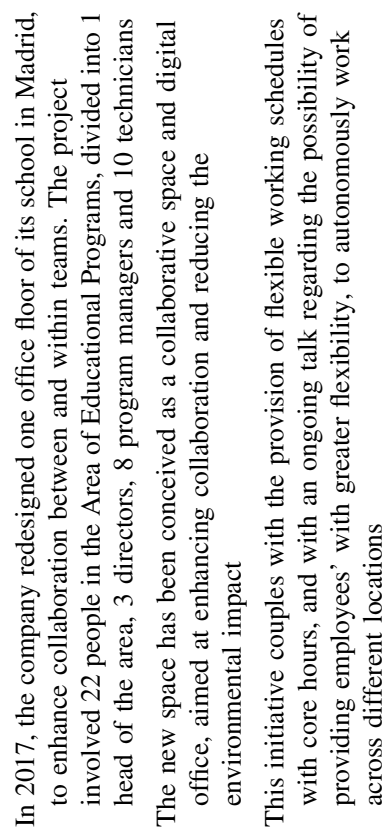 \\
\hline & 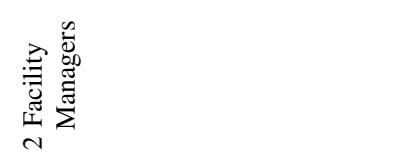 & 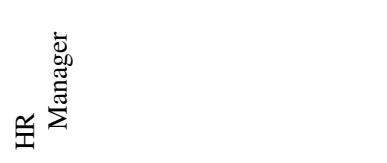 \\
\hline & 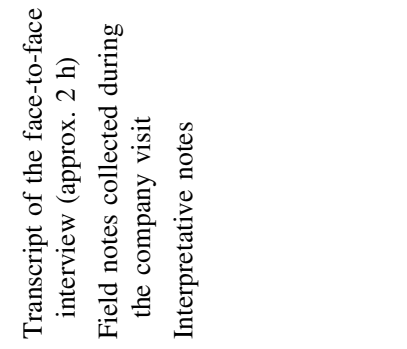 & 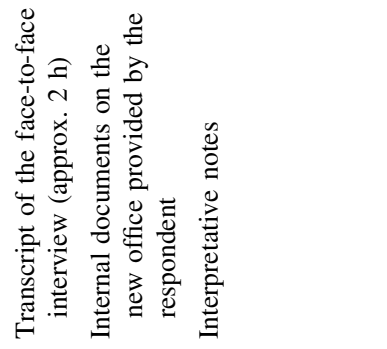 \\
\hline & $\frac{0}{\oplus}$ & 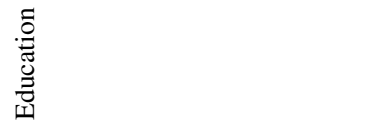 \\
\hline & $m$ & $\nabla$ \\
\hline
\end{tabular}




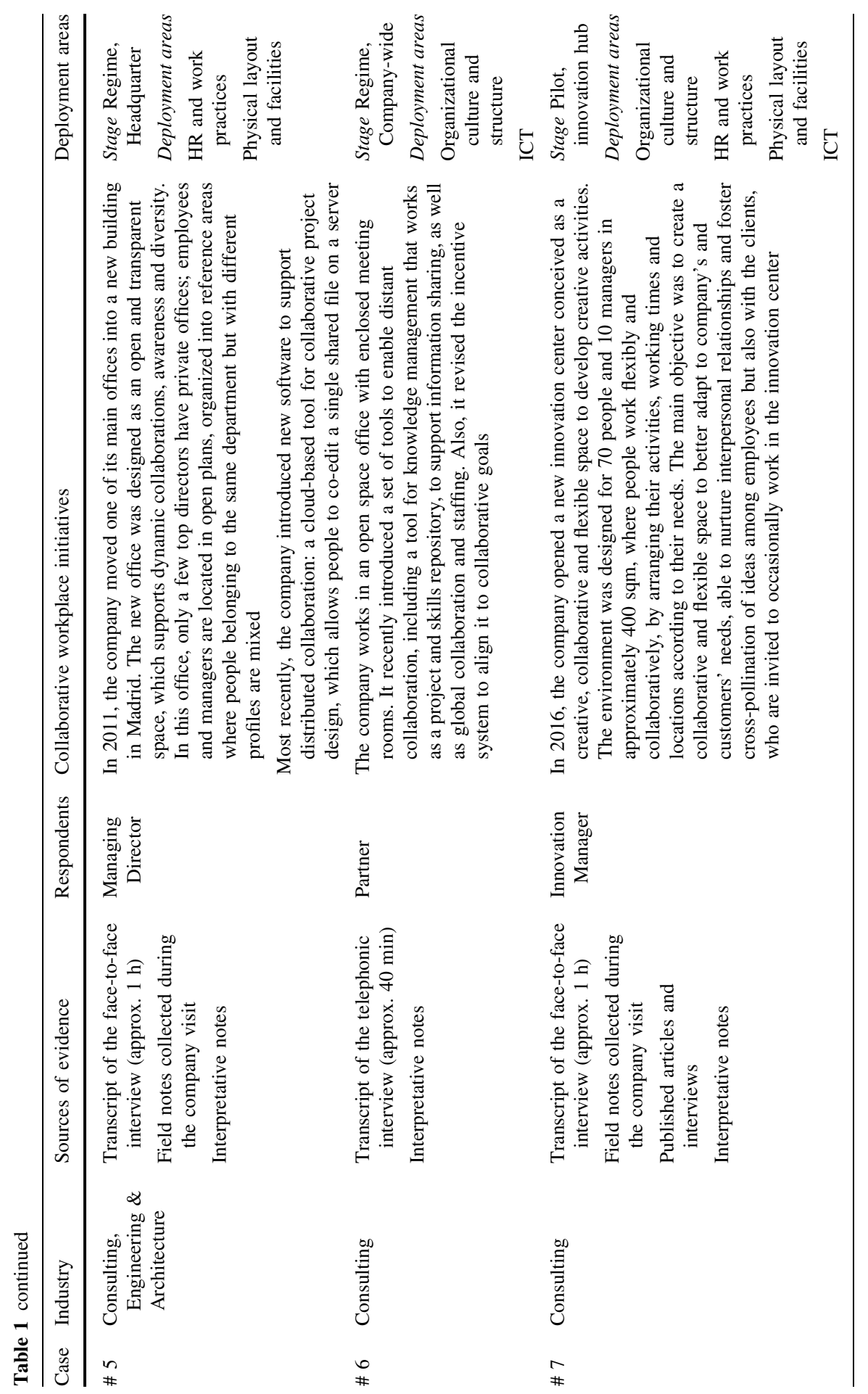




\begin{tabular}{|c|c|c|c|}
\hline \multirow[b]{2}{*}{ 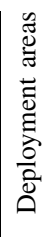 } & \multirow[b]{2}{*}{ 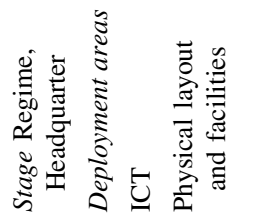 } & \multirow{2}{*}{\multicolumn{2}{|c|}{ 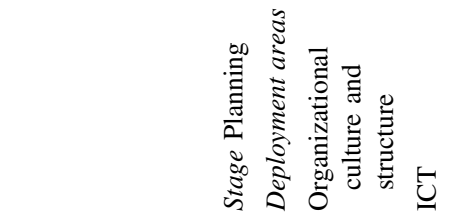 }} \\
\hline & & & \\
\hline & 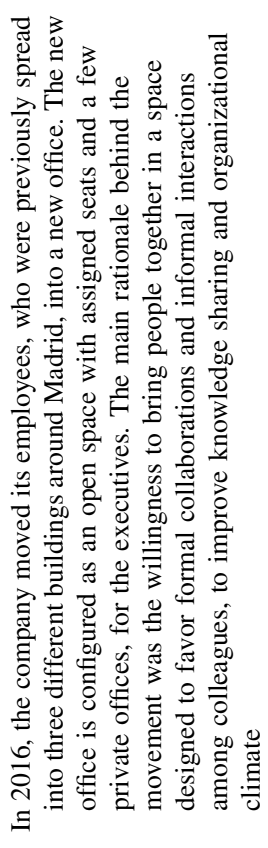 & 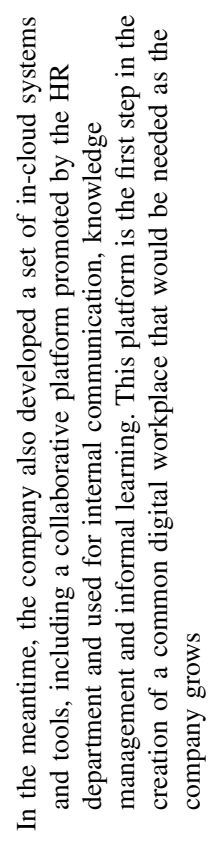 & 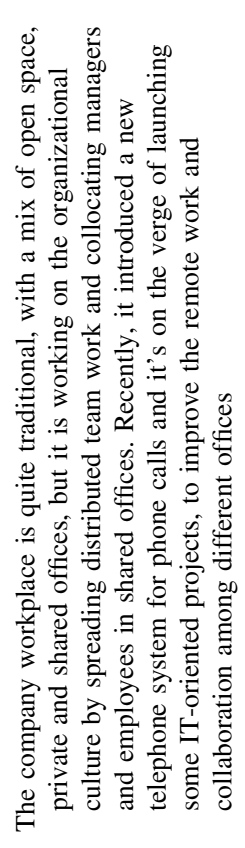 \\
\hline & 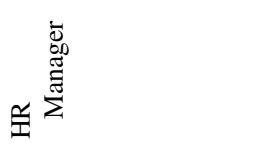 & & 哇 \\
\hline 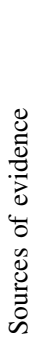 & 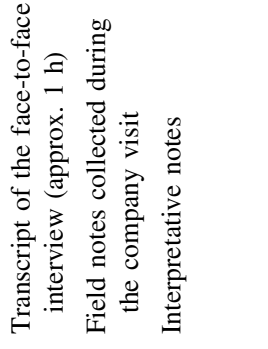 & & 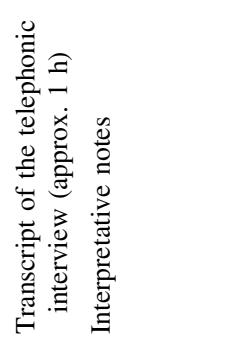 \\
\hline & 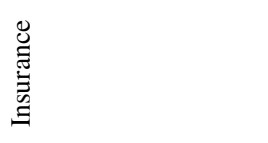 & & 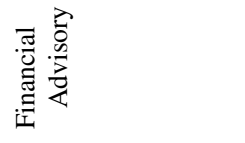 \\
\hline & $\begin{array}{l}\infty \\
\#\end{array}$ & & \# \\
\hline
\end{tabular}




\subsection{Internal barriers}

\subsubsection{Control-oriented middle management behaviors}

In the majority of the cases, CWs provide employees with some extent of autonomy to adjust their workplace location to individual and collaborative tasks. Accordingly, managers are expected to relinquish some of their control over employees' activities. Nonetheless, several respondents acknowledged control-oriented middle management among the main factors that negatively affect $\mathrm{CW}$ performance. They highlighted different dynamics through which this barrier may develop.

For example, in Companies 3 and 4, control-oriented behaviors were triggered by the workplace democratization process brought by $\mathrm{CWs}$, which threatened the power structure.

We are a young company but have very senior practices. (...) We are very traditional, too traditional in our way of working with managers with closed offices, and controlling people here (...). So, it is not easy for us to launch a project with flexible measures. Facility Manager, Company 3

The emergence of this barrier was also linked to managers' difficulties in trusting employees and to the additional challenges that managers face in guaranteeing the smooth development of work-related collaboration in flexible environments.

There are bosses that if they do not have the persons in front of them, under their view, they consider that these (people) are not working. Or they perceive that if the persons are not exactly (physically) there, then you cannot check their working time. HR Manager, Company 4

\subsubsection{Strict technology requirements}

Several respondents listed the inadequacy of existing ICT systems among the main barriers to the successful development of CWs. The inadequacy is due to the technical difficulties encountered in migrating specialized information systems to laptops, the needed investment to provide employees with ubiquitous access to information and productivity tools, and the strict security requirements that may limit information accessibility outside the conventional office. This barrier may also emerge in contexts where flexibility is bounded by main office premises, particularly in processes and functions that are mainly paper based, since CWs often adopt the paperless approach.

The big problem in this new way of working (is that there) are several systems that now we cannot move to laptop. But in a short period of time, we will recall (overcome) this problem, and then we will be able to extend the new way of working to operations. HR Manager, Company 1

The low support offered by IT systems for flexible work may also generate the perception that flexibility hampers collaborative work by limiting the possibility to quickly involve distributed workers in ongoing situations. 


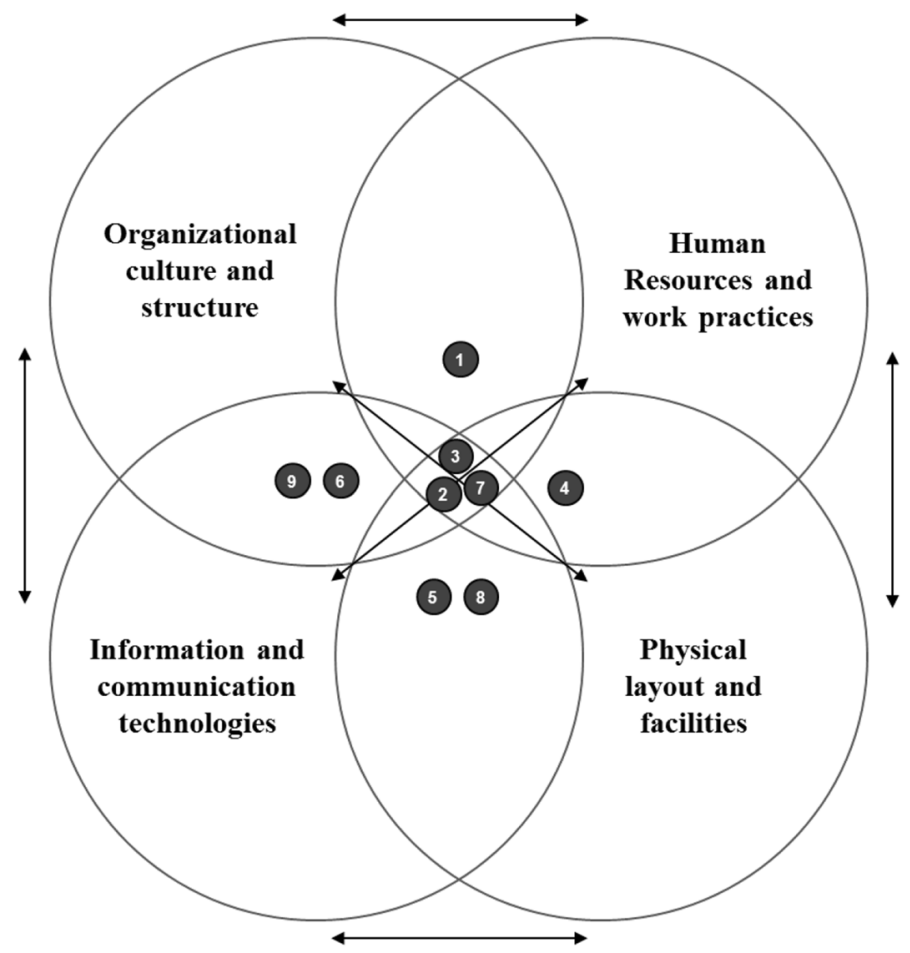

Fig. 2 Mapping CW cases: different approaches and deployment areas

(Regarding workplace flexibility) sometimes, it can slow down the work itself, because it is necessary to take precautions to get an inclusive working environment, even without having physical proximity. HR Manager, Company 9

\subsubsection{Individual resistance to change work behaviors}

Individual resistance to behavioral change is determined by personality traits and beliefs that companies and change agents cannot directly manipulate. This resistance includes the fear of the unknown and the required learning effort to change work conditions and modalities. However, the identification of the reasons behind individual resistance to change may help companies develop strategies to cope with this barrier.

Interviews in Companies 4 and 6 suggested that employees can be reluctant toward CW initiatives as they fear eventual drawbacks brought by flexibility. These include ubiquitous connectivity to work that makes people constantly accessible and generates more distractions. The normative pressure of being constantly responsive hampers collaborative behaviors and social support outside the conventional work schedules. 
Table 2 Synthesis of the empirical findings

\begin{tabular}{lll}
\hline Case & $\begin{array}{l}\text { Deployment/ Internal barriers } \\
\text { investment } \\
\text { areas }\end{array}$ & Internal enablers \\
\hline
\end{tabular}

\# 1 Organizational Strict technology requirements culture and Control-oriented middle structure

HR and work practices

$$
\text { management }
$$

Presence-based culture

Individual resistance to change

Low degree of perceived job fit

Infrastructural constraints

\# 2 Organizational culture and structure

HR and work practices

Physical layout and facilities

\section{ICT}

\# 3 Organizational

\# 4 Physical layout

\# 5 Physical layout culture and structure

HR and work practices

Physical layout and facilities

ICT and facilities

HR and work practices and facilities

ICT
\# 6 Organizational Individual resistance to change culture and structure Inadequate organizational structures

Control-oriented middle management

Individual resistance to change

Strict technology requirements

Low degree of perceived job fit

Individual resistance to change

Strict technology requirements

Control-oriented middle management

Lack of top management sponsorship

Strict technology requirements

Presence-based culture

ICT
Integrated trial-and-error approach (user type, culture, innovation and change, workplace configuration)

Internal communication

Top and middle management commitment

Budget allocation

Deployment and surveillance

Top and middle management involvement

Deployment and surveillance

Integrated trial-and-error approach (culture, innovation and change)

Top and middle management commitment

Cross-functional project team

Participative design

Internal communication

Integrated trial-and-error approach (user type, workplace layout/facilities, culture, innovation and change)

Deployment and surveillance

Budget allocation

Management-by-objective approach

Top and middle management commitment

Internal communication

Participative design

\section{Budget allocation}

Management-by-objectives

Top and middle management commitment

Integrated trial-and-error approach (culture, innovation and change)

Trial-and-error approach (incentive system)

Budget allocation 
Table 2 continued

\begin{tabular}{|c|c|c|c|}
\hline Case & $\begin{array}{l}\text { Deployment/ } \\
\text { investment } \\
\text { areas }\end{array}$ & Internal barriers & Internal enablers \\
\hline$\# 7$ & $\begin{array}{l}\text { Organizational } \\
\text { culture and } \\
\text { structure } \\
\text { HR and work } \\
\text { practices } \\
\text { Physical layout } \\
\text { and facilities } \\
\text { ICT }\end{array}$ & Individual resistance to change & $\begin{array}{l}\text { Top and middle management } \\
\text { commitment } \\
\text { Participative design approach } \\
\text { Management-by-objectives approach }\end{array}$ \\
\hline$\# 8$ & $\begin{array}{l}\text { Physical layout } \\
\text { and facilities } \\
\text { ICT }\end{array}$ & $\begin{array}{l}\text { Presence-based culture } \\
\text { Strict technology requirements } \\
\text { Control-oriented middle } \\
\text { management }\end{array}$ & $\begin{array}{l}\text { Participative design } \\
\text { Integrated trail-and-error approach } \\
\quad \text { (user type, workplace configuration) } \\
\text { Budget allocation } \\
\text { Top and middle management } \\
\text { commitment }\end{array}$ \\
\hline \# 9 & $\begin{array}{l}\text { Organizational } \\
\text { culture and } \\
\text { structure } \\
\text { ICT }\end{array}$ & $\begin{array}{l}\text { Strict technology requirements } \\
\text { Inadequate organizational structures } \\
\text { Low degree of perceived job fit } \\
\text { infrastructural constraints }\end{array}$ & - \\
\hline
\end{tabular}

One of the barriers is what they call hyper-connectivity. (...) It creates anxiety, in the sense that everybody is expecting a super-quick response to any request (...). But then people tend to overreact... like "I do not take my laptop (home) for the weekend", or "I do not take my mobile (home) for the weekend", or whatever... which is in my opinion an overreaction because I think that it is our responsibility to be accessible. But it is difficult to find the optimum equilibrium between being reachable and sitting by the phone all the time. Partner, Company 6

Additionally, the interview in Company 7 suggested that the lack of structure and reference points in CWs may present an additional challenge for some individuals who prefer a structured work environment.

We tried to test hot desking, since it is the fashion of the moment; however, hot desking did not work for us. The fact is that people need some reference points. So, we used assigned desks that can be freely used by others. Innovation Manager, Company 7

Finally, one of the main reasons behind the emergence of individual resistance to change was the impossibility to use CW to display status and identity due to the use of standard furniture and clean-desk policies that limit workplace personalization. 
They lost the "my desk". You know, "my picture", "my sons", "my plant here" and "my space". The only thing that they have here now that is "mine" is the locker where they put their things in the morning and the afternoon. When you go home, you put everything there. Facility Manager, Company 3

\subsubsection{Lack of top-management sponsorship and presence-based culture}

An additional recurring barrier was the lack of sponsorship and support displayed by top managers of the organization. For example, this consideration emerged during the interview with the HR Manager in Company 4.

The General Director does not understand flexible work; he believes that people who go to their home won't work... because they are going to do the minimum. HR Manager, Company 4

The lack of top-management sponsorship could be considered symptomatic of an unsupportive workplace culture characterized by a low degree of management flexibility and a high degree of perceived formalization. However, interviews suggested that a team culture can paradoxically obscure CW performance, particularly in those contexts where the collaborative dynamics develop throughout frequent face-to-face interactions enabled by colocation. In these cases, CWs might be perceived as undermining the extant culture and organizational identity.

From a cultural point of view, we are a very open organization; we are very collaborative, but the way we have traditionally cooperated has been the oneto-one mode, physically speaking. (...) People will question, as we reached this level of success by being together, what would happen if we just stop having more interactions in a visual way (face-to-face)? HR Manager, Company 1

\subsubsection{Low degree of perceived job fit}

Interviews highlighted the need to engage with the types of activities that are performed by knowledge workers in order to assess their suitability for CWs. A suitability assessment requires the examination of the parameters for each job that is meant to use CWs. This includes the function it serves, the degree of confidentiality required, and the amount of needed face-to-face interactions.

I surely see some difficulties (in implementing workplace flexibility). In the sense that if we take into account our main business, this is a type of job that is mainly performed in teams, and it benefits from the fact that we have daily personal contact. (...) Then, we surely have some roles, like mine in HR, which could be done more easily remotely. HR Manager, Company 9

\subsubsection{Inadequate organizational structures}

Several respondents highlighted the inadequacy of organizational structures among the main challenges to $\mathrm{CW}$ performance. Inadequacy could refer to the embedded 
rigidities, such as hierarchies, functional "silo" structures, and rigid workflows and procedures that may hamper the successful implementation of CWs.

We saw that we had problems with communication between areas and departments and with time-to-market. (...) And people perceived that there is a big gap between managers and people. Facility Manager, Company 3

An additional challenge was represented by the inadequacy of the incentive system, which does not support collaborative goals, as highlighted by the Partner in Company 6.

Another problem is when you have a business in which your incentives are relatively biased toward individualism; then, collaboration is a challenge. Partner, Company 6

\subsubsection{Infrastructural constraints}

Finally, some companies may face infrastructural constraints that limit implementation possibilities, similar to the case of Company 9.

Ours is a very small reality... We can say that the fact of being in a historical building influences a lot (our possibility to change the physical workplace to create CWs). So for us, the location is very important... Thus, it is difficult in the current space to make changes. (...) And people tend to adapt very easily. HR Manager, Company 9

\subsection{Internal enablers}

\subsubsection{Top and middle management commitment}

Top and middle managers' commitment to CW was identified as an enabler in six companies in our sample. Those were the ones driving the cultural change within the company, leading by example, including possibly relinquishing the privilege of the private office.

(The change is driven) from the CEO. If the CEO is not convinced about this kind of break, this (the development of CWs) won't move. Facility Manager, Company 3

Thus, empirical findings suggest that organizations might preliminarily implement a set of initiatives to engage the senior leaders in shaping CW strategies. This creates an environment conducive for other types of change management initiatives that target middle managers.

\subsubsection{Integrated trial-and-error approach}

Interviews suggested the effectiveness of using a trial-and-error approach throughout the whole testing phase. Companies can run pilots that are implemented at 
different scales in which they repeatedly introduce interventions in one or more of the following areas until they reach the desired results.

4.2.2.1 Culture, innovation and change Some case companies set up preliminary initiatives to change the organizational culture. For example, these initiatives included a series of workshops with managers to help them develop an attitude toward collaborative and flexible ways of working and charge them with social engineering values regarding new work practices and new roles.

The (name of the change management initiative) is a project that has a lot of targets, but one of these targets is to develop the soft skills of the managers for managing others in a different way. Different ways mean a more flexible way, a more open way, a more collaborative way. Innovation Manager, Company 1

\subsubsection{Workplace configuration Companies may experiment with different} approaches in their workplace by creating different solutions in the physical and digital dimensions of CWs to support heterogeneous individual tasks, team activities and job types.

For example, here we tested this (structure creating an enclosed area for small teams) that did not work very, very well, so we will probably change it. This one was much better because it is much more confidential. (...). This is one of the (zones that) we are going to improve so that it can have more confidentiality that we have not gained here yet. HR Manager, Company 3

Companies may also experiment and provide some structure using zoning to divide and control functions and activities and combine spatial distinctions. These shared spaces are an attempt to create a better fit between the available space and work processes.

4.2.2.3 Incentive system To ensure CW performance, companies need to align the incentive system to the collaborative goals. This must be done in a way to ensure concurrent individual performance and accountability.

(Talking about the need to revise the incentive system) you need to find the optimal (incentive system) setup, between mutualized factors and individual performance and accountability, while at the same time fostering collaboration, and this is a challenge. Managing Partner, Company 6

4.2.2.4 User types Finally, different types of people could be brought into CW pilots in order to understand which types of jobs are the most conducive to the new workplace.

We tried to search for different profiles of the departments. (...) The main reason is to test this model with different kinds of people, not only with technicians, not only with human resources, but a mix of sellers, commercial, finance and very different profiles. Facility Manager, Company 3 


\subsubsection{Budget allocation}

CWs usually require significant investment in terms of physical and technological infrastructures in order to provide adequate support and flexible work practices across organizational boundaries. Therefore, companies need to allocate budgets toward infrastructural development and for equipping people with the necessary tools, the relevant training, and the appropriate administrative and technical support.

You also need to invest in tools (...). You need, for example, to also change the fixed phone system completely. (...) We are investing 1 million euros now to change the laptop. (...) You have to invest a lot of money. Facility Manager, Company 3

In addition, companies should allocate part of the budget to sustaining the aforementioned change management initiatives that are aimed at adjusting managers' mindsets to collaborative and flexible ways of working.

\subsubsection{Participative design approach}

Interviews also suggested that individual resistance could be exacerbated by employees' perception that a change is being pushed from the top-down. However, this perception may be manipulated by involving employees in the change management process from the early stages through the adoption of a participative design approach, similar to the case of Company 7.

It is not true that people hate to change. They hate to be changed by others. But this is exactly what we are trying to get here, in the Innovation site: facilitate people through the provision of the proper space. Empower them in a way that they become the agents of change. Innovation Manager, Company 7

For example, this enabler was enacted through the use of surveys aimed at detecting specific issues to be addressed throughout $\mathrm{CW}$ initiatives. Change leaders that have the responsibility to deliver and receive managerial feedback throughout the whole process can also be used.

\subsubsection{Internal communication}

Employees' participation is also enabled by internal communication on the planned interventions. This allows companies and their managers to collect feedback and suggestions for improvements in a timely manner and use work-related arguments, as noted by the HR manager of Company 4 .

People become very nervous when they get to know that they are going to change their place: where am I going to stay, how this is going to change.... Thus, the more (first-hand) information they get and the more explanations you provide, the better it is. HR Manager, Company 4 
Companies may also use internal communications to convey employee empowerment, which anchors $\mathrm{CW}$ to concepts that broaden the scope of the implemented initiatives, such as freedom, flexibility and innovation.

From a cultural point of view, we do not want to refer to (the pilot $\mathrm{CW}$ initiative) as 'remote work' because we just want to talk about flexibility and about freedom. The freedom to autonomously arrange your work according to your objectives. HR Manager, Company 1

\subsubsection{Management-by-objective approach}

The performed interviews suggested that companies may counterbalance the lack of structure that characterizes CWs and overcome control-oriented managers' behaviors that might emerge through the identification and provision of clear objectives that employees need to achieve. Stated differently, CWs are configured as outputdriven environments in which the focus has shifted from observable behaviors (such as time spent at the desk) to the work outcomes. Thus, people become more responsible and accountable for their own results.

The person has to be a responsible person as well, as he should be capable of organizing himself in terms of work. The boss has to be a boss who delegates, who is able to set and being oriented toward results, and who is able to say to the person what he has to do. HR Manager, Company 3

\subsubsection{Deployment and surveillance}

Finally, a factor that emerged as an important enabler for CW performance was the implementation and the use of key performance indicators linked with the initiative drivers. For example, Company 3 introduced surveys on job satisfaction and sensors aimed at detecting the desk occupancy rate to monitor changes in work behaviors.

We have installed movement sensors in the desks. (...) We are going to use this information from the position of sensors to check the occupancy and the behavior of the people. (...) We want to know the dynamics of this building to improve and increase the occupancy and to check if the behavior of the people is dynamic or not. Facility Manager, Company 3

\subsubsection{Cross-functional project team}

In the companies where the implementation of CWs involved different deployment areas, respondents often relate the success of these initiatives to the engagement of cross-functional project teams, working together during the design and implementation phases. These cross-functional teams often involved people from human resources, facilities, IT departments and business units. This guarantees that workplace interventions are designed in a way that the physical workplace, organizational policies and ICT standards and infrastructures are aligned and 
adequately support the specific organization's configurational structures, tasks and complexity.

We have been working with human resources from the beginning, almost 1 year so far. We have been sponsors of the change because the main change at that moment was this space but very close to human resources. Facility Manager, Company 3

\section{Discussion}

\subsection{Contingency factors in collaborative workplaces}

The first objective of this paper was to provide a systematic overview of the internal contingency factors that affect $\mathrm{CW}$ performance in established service companies.

Our findings show that despite the existence of different approaches to $\mathrm{CW}$ initiatives, a number of recurring barriers and enablers can be identified. The barriers include control-oriented middle management behaviors, lack of topmanagement sponsorship, presence-based culture, inadequate organizational structures, strict technology requirements, low degree of perceived job fit, individual resistance to change, and infrastructural constraints. The enablers comprise top and middle management commitment, internal communication, crossfunctional project team, participative design approach, integrated trial-and-error approach, management-by-objective system, budget allocation and deployment and surveillance.

The identified barriers can be mapped into the modified version of Chan, Lawrence and Backman's model based on their reference deployment area (Fig. 3). The map reveals an unbalanced distribution, with most of the barriers concentrated in the organizational culture and structure area.

Within this area, control-oriented middle management was found to be the most relevant barrier. This emerges when managerial behaviors focused on the direct control of employees' activities collide with the interventions in other "configurational" deployment areas, i.e., the physical workplace, ICT and work practices. Additional barriers that refer to the elements characterizing an organization's culture and structure include the lack of top-management sponsorship, presencebased culture, inadequate organizational structures and resistance to change.

Prior research suggested that CWs might be used to dismantle consolidated routines and work practices to promote new collaborative dynamics driven by customer orientation (O'Neill and McGuirk 2003; Waber et al. 2014). However, studies also suggested that $\mathrm{CW}$ features can bring some unintended consequences that might hamper collaborative and innovative behaviors (Parker 2016; Baldry et al. 1997; Carlopio and Gardner 1992; Allen 1977).

Our study contributes to this debate by adding a contingency perspective that identifies the factors that influence $\mathrm{CW}$ performance. Our findings suggest that if not counterbalanced by the identified enablers, the detected barriers reinforce each other. This leads to the emergence of interactional effects between deployment areas 
that might feed the tensions that are described in the next paragraph and highlighted in Fig. 4.

\subsection{Tensions arising between deployment areas}

\subsubsection{Emergence of the autonomy control tension}

CWs are often designed as open and transparent environments that remove elements that signal organizational boundaries to encourage autonomous collaboration across hierarchies and functions (Vilnai-Yavetz 2005; Elsbach and Pratt 2007). However, in open and transparent CWs, people and group performances are constantly visible, reinforcing mutual expectations of efficiency and accountability (Parker 2016; Goffman 1959). Furthermore, the status loss brought by the low level of personalization in CWs has been shown to trigger managers' behaviors aimed at reinforcing hierarchies and structures through exacerbated control (Carlopio and Gardner 1992). Higher control, in turn, hampers innovation performance, as experimentation and risk-taking behaviors are inhibited in the context where employees feel constantly "under the spotlight" (Bernstein 2008).

Accountability in CWs is also created by digital technologies through the ubiquitous connectivity that makes people constantly accessible. This generates more distractions and the normative pressure of being constantly responsive (ten Brummelhuis et al. 2012; Katz and Aarhus 2002). Empirical findings suggested that people may react to increased exhaustion with withdrawal behaviors that negatively affect workgroup relations with dynamics that resemble those identified by Lautsch and colleagues in their study on workplace flexibility (Lautsch et al. 2009).

\subsubsection{Emergence of the exploration-exploitation tension}

Taking on a knowledge perspective, CWs are designed to foster exploratory learning through a combination of initiatives that increase the likelihood of the cross-pollination of ideas between people from different groups. However, companies also rely on a different type of exploitative learning that limits the out-of-the-box thinking but increases the likelihood of getting quick results by effectively employing the knowledge stock that is available within group boundaries (Coradi et al. 2015a; Waber et al. 2014).

Therefore, CWs could be perceived by people and companies as "groupshrinking" spaces that hamper the development of important group dynamics supported by face-to-face interactions. This circumstance was highlighted by respondents in Companies 2, 5 and 9, where group-member colocation was identified as a pre-condition for team agility. Additionally, an open and transparent $\mathrm{CW}$ combined with hot desking and the extensive use of e-communication might generate a restless environment that hampers creative and concentration-demanding tasks (Bosch-Sijtsema et al. 2010). 


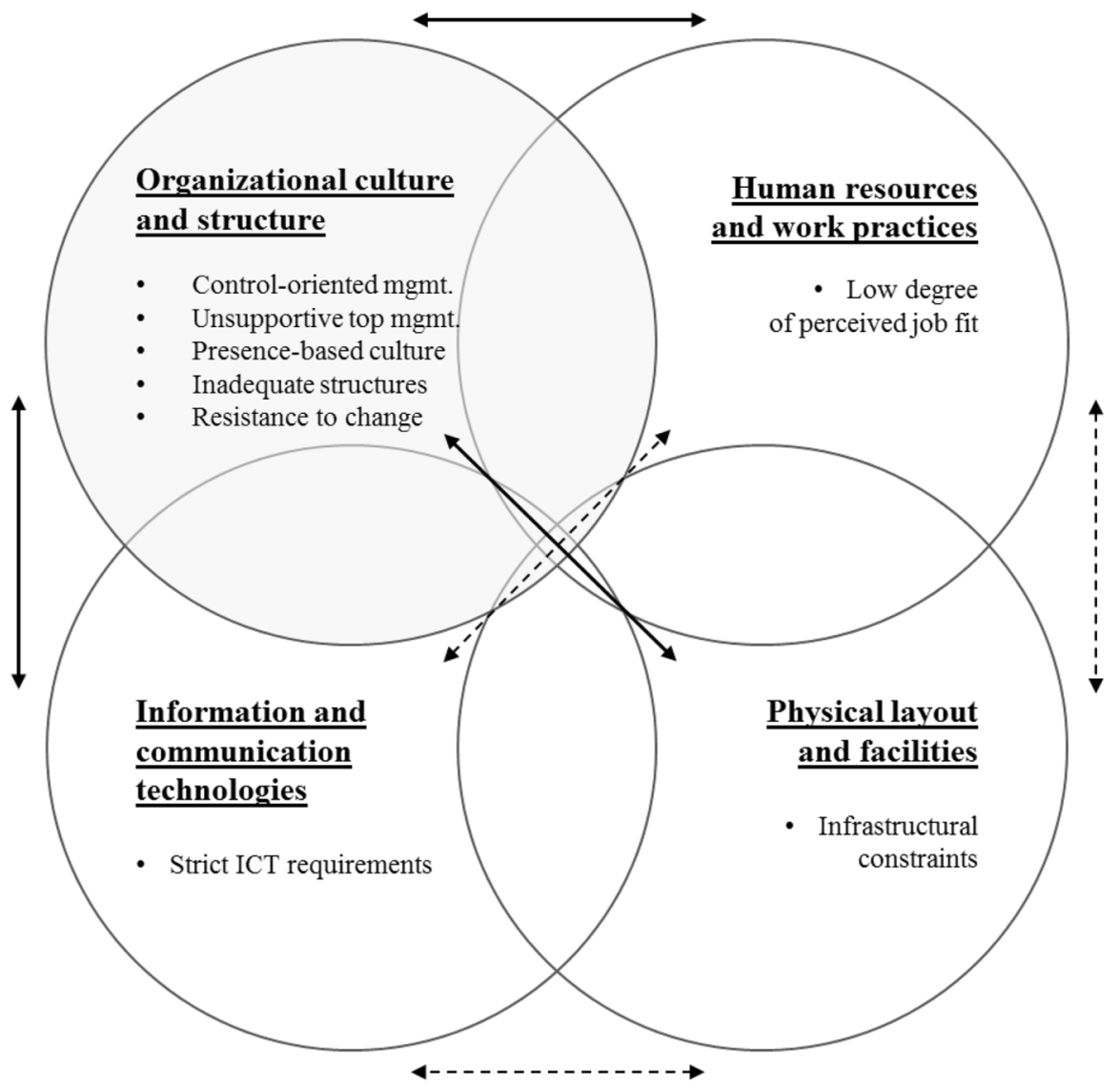

Fig. 3 Map of the internal barriers

\subsection{How companies might leverage enablers to cope with tensions}

Our analysis suggested that companies might leverage some enablers to mitigate the mutual reinforcement of the internal barriers and avoid inconsistencies. Several companies in the sample employ pilots that are combined with trial-and-error and participative approaches to nurture CW concepts in small-scale contexts, where local management is committed, employees are willing to be actively involved and innovate, and the climate is conducive to change (Apgar 1998).

Furthermore, interviews suggested that before implementing CWs, companies should invest in managerial training and in some preliminary interventions aimed at simplifying the existing organizational structures. These interventions include the simplification of extant work and HR procedures and the broadening of the information access. Moreover, to spearhead a change in managerial behaviors, companies should preliminarily design and employ a management-by-objective reward system that favors the shift toward a collaborative, output-driven 


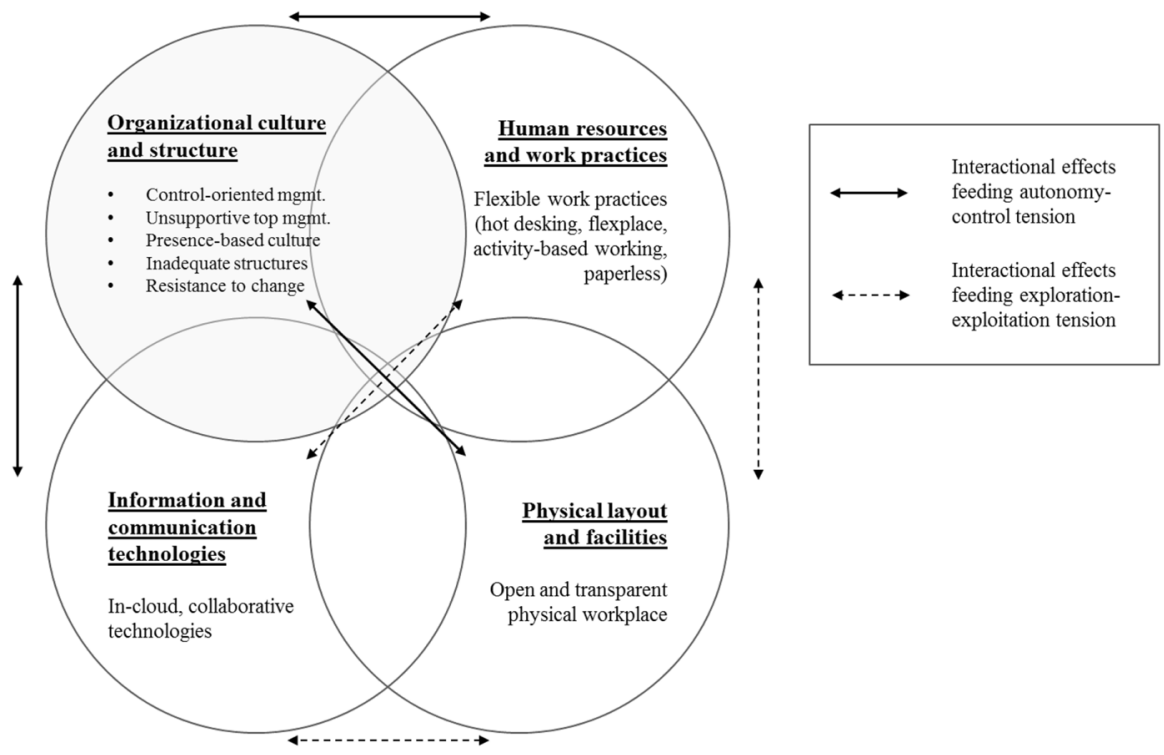

Fig. 4 Tensions generating from the misalignment between deployment areas

environment. Employees can be flexible since their evaluations are based on the delivered outcomes and collaborative goals and not on directly observable behaviors.

In addition, companies should employ CWs to sustain exploitative dynamics, exploratory dynamics, stimulation and focus through the use of balanced layouts that carefully match job parameters (including collaboration requirements) with the specific CW configurations. To avoid potential mismatches, most of the companies in our sample employed a trial-and-error approach on workplace configuration and user types that were implemented throughout pilot projects. Companies first implemented this approach by involving the functions with employees who were used to working flexibly and communicating with customers and colleagues using various technologies. The input of these test users is important to drive the $\mathrm{CW}$ initiatives in a bottom-up manner. Employees contribute with a participative design approach, and managers guide the implementation.

Finally, to ensure alignment among work practices, HR systems, technologies, facilities and layouts, companies in the sample also relied on multidisciplinary project teams (Tagliaro and Ciaramella 2016) involving facilities, HR, IT department and lines of business.

\section{Conclusions}

This paper contributes to the innovation and knowledge management literature by providing new evidence on the debate on the abilities of workplaces designed as collaborative platforms to support innovation and new ways of working (Moultrie 
et al. 2007; Bitner 1992; McCoy 2005; Kristensen 2004; Parker 2016) in the context of established service companies. Our contribution is three-fold.: (1) we added a contingency perspective by identifying the factors that hinder or contribute to $\mathrm{CW}$ performance; (2) we highlighted the mechanisms through which the barriers may reinforce themselves and generate tensions between deployment areas; and (3) we explore how companies might employ enablers to mitigate these tensions. By disclosing the mechanisms through which these tensions develop, we also contribute to workplace design research. We answered the call launched by Chan and colleagues for more research that digs into the interactional effects among workplace design areas (Chan et al. 2007).

The practical relevance of this work lies in the provision of some guidelines for companies and managers to guide the implementation and the development of $\mathrm{CW}$ initiatives.

However, we should acknowledge some limitations of this study. First, the unbalanced distribution of the contingency factors might be justified by the type of respondents. They displayed high-level views on the $\mathrm{CW}$ initiatives that focused on "soft" aspects rather than on operational work. Therefore, further research should investigate employees' perspectives on the contingency factors to better engage the job parameters that affect the perceived degree of job fit to CW. Second, CWs involved a plurality of aspects, but our findings relied on a limited number of interviews and respondent types for each case. Therefore, their perspectives on the $\mathrm{CW}$ phenomenon should be validated through additional interviews with managers and employees from the case companies. Finally, our research suggested the existence of two tensions that might be embedded in the $\mathrm{CW}$ design: autonomy control and exploration exploitation. Further research would dig into these tensions to disclose the mechanisms through which paradoxes might develop and the strategies that managers may employ to fuel creativity and innovation while avoiding inconsistencies (Schumpeter 1934).

Open Access This article is distributed under the terms of the Creative Commons Attribution 4.0 International License (http://creativecommons.org/licenses/by/4.0/), which permits unrestricted use, distribution, and reproduction in any medium, provided you give appropriate credit to the original author(s) and the source, provide a link to the Creative Commons license, and indicate if changes were made.

\section{References}

Allen TJ (1977) Managing the flow of technology. The MIT Press, Cambridge, MA

Apgar M (1998) The alternative workplace: changing where and how people work. Harvard Business Review 76(3):121-136

Baldry C, Bain P, Taylor P (1997) Sick or tired? Working in the modern office. Work Employ Soc 11(3):519-539

Barley SR, Kunda G (2001) Bringing work back in. Organ Sci 12(1):76-95

Bean CJ, Eisenberg EM (2006) Employee sensemaking in the transition to nomadic work. J Org Change Manag 19(2):210-223

Bernstein E (2008) The transparency trap. Harv Bus Rev 92(10):58-66

Bitner MJ (1992) Servicescapes: the Impact of physical surroundings on customers and employees. J Mark 56:57-71 
Bosch-Sijtsema PM, Ruohomäki V, Vartiainen M (2010) Multi-locational knowledge workers in the office. N Technol Work Employ 25(3):183-195

Bosch-Sijtsema PM et al (2011) A framework to analyze knowledge work in distributed teams. Group Org Manag 36(3):275-307

Boutellier R et al (2008) Impact of office layout on communication in a science-driven business. R \& D Manag 38(4):372-391

Brennan A, Chugh JS, Kline T (2002) Traditional versus open office design: a longitudinal field study. Environ Behav 34(3):279-299

Carlopio JR, Gardner D (1992) Direct and interactive effects of the physical work environment on attitudes. Environ Behav 24(5):579-601

Chan JK, Beckman SL, Lawrence PG (2007) Workplace design: a new managerial imperative. Calif Manag Rev 49(2):6-22

Chen W, McDonald S (2015) Do networked workers have more control? The implications of teamwork, telework, ICTs, and social capital for job decision latitude. Am Behav Sci 59(4):492-507

Collins AM, Hislop D, Cartwright S (2016) Social support in the workplace between teleworkers, officebased colleagues and supervisors. N Technol Work Employ 31(2):161-175

Coradi A, Heinzen M, Boutellier R (2015a) A longitudinal study of workspace design for knowledge exploration and exploitation in the research and development process. Creat Innov Manag 24(1):55-71

Coradi A, Heinzen M, Boutellier R (2015b) Designing workspaces for cross-functional knowledgesharing in R\&D: The "co-location pilot" of Novartis. J Knowl Manag 19(2):236-256

Davenport TH, Prusak L (2000) Working knowledge: how organizations manage what they know. In: ACM: Ubiquity, pp. 1-15

Davenport TH, Thomas RJ, Cantrell S (2002) The mysterious art and science of knowledge-worker performance. MIT Sloan Manag Rev 44(1):22-30

Eisenhardt KM (1989) Building theories from case study research. Acad Manag Rev 14(4):532-550

Elsbach KD, Bechky BA (2007) It's more than a desk: working smarter through leveraged office design. Calif Manag Rev 49(2):80-102

Elsbach KD, Pratt MG (2007) The physical environment in organizations. Acad Manag Ann 1(1):181-224

Fleming L (2004) Perfecting cross-pollination. Harv Bus Rev 82(9):22-24

Gajendran RS, Harrison DA (2007) The good, the bad, and the unknown about telecommuting: Metaanalysis of psychological mediators and individual consequences. J Appl Psychol 92:1524-1541

Gerdenitsch C, Kubicek B, Korunka C (2015) Control in flexible working arrangements. J Pers Psychol 14(2):61-69

Gioia DA, Corley KG, Hamilton AL (2012) Seeking qualitative rigor in inductive research: notes on the Gioia methodology. Org Res Methods 16(1):15-31

Goffman E (1959) The presentation of self in everyday life. Penguin Books, Harmondsworth

Haner U-E, Bakke JW (2008) Proximity, mobility and aesthetics in strategies for innovation management. Int J Entrep Innov Manag 8(2):168-183

HillC WL, Gareth RJ (2009) Essentials of strategic management. South-Western, ed. Cengage Learning, Mason, $\mathrm{OH}$

Hoeven CL, Van Zoonen W (2015) Flexible work designs and employee well-being: examining the effects of resources and demands. N Technol Work Employ 30(3):237-255

Katz JE, Aarhus MA (2002) Making meaning of mobiles: a theory of apparatgeist. In: Katz JE, Aarhus MA (eds) Perpetual contact: mobile communication, private talk, public performance. Cambridge University Press, Cambridge, pp 301-318

Kristensen T (2004) The physical context of creativity. Creat Innov Manag 13(2):89-96

Lautsch BA, Kossek EE, Eaton SC (2009) Supervisory approaches and paradoxes in managing telecommuting implementation. Hum Relat 62(6):795-827

Lee SY (2016) Creative workplace characteristics and innovative start-up companies. Facilities 34(7/ 8):413-432

McElroy JC, Morrow PC (2010) Employee reactions to office redesign: a naturally occurring quasi-field experiment in a multi-generational setting. Hum Relat 63(5):609-636

McCoy JM (2005) Linking the physical work environment to creative context. J Creat Behav 39(3):169-191 
Miller WL, Crabtree BF (1992) Primary care research: a multi method typology and qualitative road map. In: Crabtree BJ, Miller WL (eds) Doing qualitative research, vol 3. Sage Publishing, Newbury Park, CA, pp 3-30

Moultrie J et al (2007) Innovation spaces: towards a framework for understanding the role of the physical environment in innovation. Creat Innov Manag 16(1):53-65

Nonaka I (1994) A dynamic theory of organizational knowledge creation. Organ Sci 5(1):14-37

Nonaka I, Konno N (1998) The concept of "Ba". Calif Manag Rev 40(3):40-54

O'Neill P, McGuirk P (2003) Reconfiguring the CBD: work and discourses of design in Sydney's office space. Urban Stud 40(9):1751-1767

Oksanen K, Ståhle P (2013) Physical environment as a source for innovation: investigating the attributes of innovative space. J Knowl Manag 17(6):815-827

Oldham GR, Brass DJ (1979) Employee reactions to an open-plan office: a naturally occurring quasiexperiment. Adm Sci Q 24(2):267-284

Ostrom AL et al (2010) Moving forward and making a difference: research priorities for the science of service. J Serv Res 13(1):4-36

Parker LD (2016) From scientific to activity based office management: A mirage of change. J Account Org Change 12(2):177-202

Penn A, Desyllas J, Vaughan L (1997) The space of innovation. Paper presented at the First International Space Syntax Symposium, pp 12.1-12.24

Pentland AS (2012) The new science of building great teams. Harv Bus Rev 90(4):61-70

Schumpeter JA (1934) The theory of economic development. Harvard University Press, Cambridge, MA

Stryker JB, Santoro MD, Farris GF (2012) Creating collaboration opportunity: designing the physical workplace to promote high-tech team communication. IEEE Trans Eng Manag 59(4):609-620

Tagliaro C, Ciaramella A (2016) Experiencing smart working: a case study on workplace change management in Italy. J Corp Real Estate 18(3):194-208

Ten Brummelhuis LL, Halbesleben JRB, Prabhu V (2011) Development and validation of the New Ways of Working scale. Paper presented at the Annual Meeting of the Southern Management Association, Savannah, GA

Ten Brummelhuis LL et al (2012) Do new ways of working foster work engagement? Psicothema 24(1):113-120

Van Der Voordt TJM (2004) Productivity and employee satisfaction in flexible workplaces. J Corp Real Estate 6(2):133-148

Vilnai-Yavetz I (2005) Instrumentality aesthetics, and symbolism of office design. Environ Behav 37(4):533-551

Vischer JC (2007) The concept of workplace performance and its value to managers. Calif Manag Rev 49(2):62-79

Vischer JC (2011) User empowerment in workspace change. In: Finch E (ed) Facilities change management. Wiley-Blackwell, Chichester, pp 123-136

Waber B, Magnolfi J, Lindsay G (2014) Workspaces that move people. Harv Bus Rev 92:69-77

Yin RK (1989) Case study research. Sage Publishing, Newbury Park, CA 